\title{
BLOOD VOLUME IN CONGESTIVE HEART FAILURE '
}

\author{
BY R. W. GUNTON 2 AND W. PAUL \\ (From the Department of Medicine and Radioisotope Laboratory, University of Toronto, and \\ the Medical Service, Toronto General Hospital, Toronto, Canada)
}

(Submitted for publication July 30, 1954; accepted September 8, 1954)

Discussions of the mechanism of congestive heart failure usually involve a consideration of the blood volume $(1,2)$. The problem has engaged the attention of many investigators: some have found blood volume to be increased in congestive heart failure $(3-7)$; others have found it to be normal $(8,9)$. This report is made to record the authors' observations in a study of 102 patients in heart failure.

In this investigation the answers to three questions were sought: 1 . Is the blood volume of patients in congestive heart failure different from the blood volume of control patients without heart disease? 2. (a) Is there a change in blood volume as patients improve from heart failure to the compensated state? (b) If so, can this change be attributed solely to improvement in circulatory function or may it be due to bed rest alone? There are several reports that a reduction in blood volume occurs with inactivity or bed rest (10-12). 3 . Is there a change in blood volume in patients who revert spontaneously from a state of compensation to heart failure? In the literature there are many answers to questions 1 and 2 (a) but little information relative to questions $2(\mathrm{~b})$ and 3 . In our study particular attention has been devoted to these two questions.

\section{METHODS}

Blood volume studies were made on 102 patients in heart failure and on 107 control patients. The absolute criterion for the diagnosis of congestive heart failure was unequivocal elevation of jugular venous pressure as determined by clinical examination. No patient was included in this series in whom this finding was absent or questionable. These patients had, in addition, the other signs of heart failure : orthopnea, basal râles, cardiac and hepatic enlargement, and peripheral edema. A few lacked detectable edema but presented all the other manifestations; some of the patients with pulmonary heart

\footnotetext{
1 This work was supported by a Grant from the National Research Council, Canada.

2 Senior Medical Research Fellow, National Research Council, Canada.
}

disease did not have basal râles. All the patients were acutely ill and presented the clinical picture of advanced "right-sided" heart failure. The etiological types of heart disease and their frequency were: arteriosclerotic, 34; hypertensive and arteriosclerotic, 26; hypertensive, 14; rheumatic, 14; pulmonary, 11; congenital, 1; luetic, 1; amyloid, 1.

An initial blood volume determination was made usually within twelve hours of admission to hospital. In as many cases as possible it was repeated when all clinical signs of failure had disappeared.

Control patients were selected who did not have any known disease of heart, lungs or blood and who were not acutely ill. The commonest diagnoses in this group were diabetes, peptic ulcer, epilepsy and other neurological disorders, and convalescent pneumonia. In fifty-five of the control patients who remained largely confined to bed during their hospital stay, an initial blood volume determination was made shortly after admission and was repeated after a varying interval of time. These patients were not strictly immobilized; some had bathroom privileges. It was considered that their degree of activity did not differ markedly from that of patients recovering from heart failure. These patients were not controls in the strictest sense of that term because they did not have dietary salt restriction, digitalis and diuretics as did the patients in congestive heart failure. The repeat blood volume determinations on these subjects provided a group of paired observations to test the reproducibility of the method and to show whether significant changes in blood volume would result from ordinary bed rest.

In some of the cardiac patients the opportunity occurred to measure the blood volume at the time of readmission in heart failure, their blood volume having been determined on a prior occasion in the compensated state. An interval of several months often separated the two admissions. No control observations were made for this group.

Blood volume was determined by the $\mathrm{P}^{*}$ tagged red blood cell method. Eight or ten cubic centimeters of the subject's blood were incubated for forty-five to sixty minutes at $37^{\circ} \mathrm{C}$. with 50 to 75 microcuries of $\mathrm{P}^{* 0}$ in a sterile rubber-capped tube. The plasma was removed after centrifugation and the cells washed twice with sterile isotonic saline solution. The cells were then resuspended in saline to approximately the original volume and, without delay, a $5.0 \mathrm{cc}$. aliquot was injected intravenously from a calibrated syringe. One venous blood sample was drawn from the opposite arm vein ten to fifteen minutes after injection, using dry powdered heparin as the anticoagulant. It was found, using this 
technique of preparation, that the amount of $P$ in the supernatant saline of the final tagged-cell suspension comprised approximately 2 per cent of the injected dose by comparison against a standard uranium source. No correction was made for this extra-cellular $P^{*}$ in the calculation. It was found also, as reported by others (6), that the radioactivity of venous blood measured at fifteen-minute intervals for a period of one hour after the intravenous injection did not vary significantly from the ten to fifteen-minute value even in patients with heart failure. In the routine procedure the single sample was therefore used, it being considered that mixing was complete at that time.

In the counting technique liquid samples were used. One cubic centimeter of the tagged-cell suspension ("standard") was first hemolyzed and then diluted to $200 \mathrm{cc}$. in 18 per cent dextrose, as described by Reid and Orr (13). The venous blood sample was untreated. These samples were placed in specially prepared pyrex glass beakers of identical internal diameter mounted horizontally below the end window of a Geiger tube. The depth of the fluid in the beakers was $12 \mathrm{~mm}$. so that the principle of "infinite thickness" was employed (13). Five thousand to six thousand counts were recorded at a rate of counting twenty times background. Counting of the venous blood sample was interrupted at five-minute intervals for stirring to prevent settling of intact red cells away from the important upper layers of fluid. The hematocrit of venous blood was read from duplicate samples after centrifugation at 3,000 r.p.m. for forty minutes. No correction was applied for trapped plasma. The calculations were made as follows: the ratio of venous to body hematocrit may not be identical in these three groups of patients will be considered in the discussion.

\section{RESULTS}

\section{Heart failure group versus control group}

The average values of total, red cell, and plasma volume for the group of 102 patients in heart failure are compared with those of 107 control patients in Table I. Males in heart failure have an excess of $983 \mathrm{cc}$. of total volume over the controls; females an excess of $1,313 \mathrm{cc}$. Since the hematocrit values are very nearly identical in the two groups, the excess is shared by the red cell and plasma fractions in about the same proportion as in normal blood.

The values for total, red cell and plasma volumes, expressed in cc. per kilogram of body weight, of the 107 control patients and of the survivors in the heart failure group in whom it was possible to determine "dry" body weight in the compensated state are given in Table II. Males in heart failure had a mean total blood volume of 90.7 cc. per $\mathrm{Kg}$.; male controls 69.8 cc. per $\mathrm{Kg}$. Females in heart failure had a mean total blood volume of $88.2 \mathrm{cc}$. per $\mathrm{Kg}$.; female controls 60.6

$$
\text { Total Blood Volume } c c .=\frac{\text { counts per min. (standard) } \times 5.0 \text { (vol. injected) } \times 200 \text { (dil. factor) }}{\text { counts per min. (venous sample) }}
$$

Red Cell Volume $=$ Total Blood Volume $\times$ Hematocrit Plasma Volume $=$ Total Blood Volume - Red Cell Volume.

The technical accuracy of the method was tested in vitro on bottles of blood, care being taken to arrange that the amount of radicactivity in the samples was similar to that in the measurements on humans. In nine successive experiments the mean difference of the determined from actual volume was -0.06 per cent (Standard Deviation \pm 4.08 per cent). This test of accuracy does not include physiological errors. It is merely a test of the accuracy of the diluting and counting techniques.

Because this is a tagged red cell method, only the red cell volume will be directly measured. The values for total volume and plasma volume are dependent on the venous hematocrit. Because total body hematocrit is probably lower than venous hematocrit (14-16) values given here for total volume and plasma volume may be low. In this report conclusions are based on differences in volumes measured by identical methods. If the ratio of body to venous hematocrit is the same in control patients, patients in heart failure, and patients in the compensated state, the conclusions based on the differences observed are valid. The important observation (6) that cc. per $\mathrm{Kg}$. The mean differences were significant : males, $t=7.9 ; \mathrm{P}<.001$; females, $t=6.5$; $\mathbf{P}<.001$

TABLE I

Comparison of blood volume: Heart failure vs. controls *

\begin{tabular}{lccr}
\hline & \multicolumn{3}{c}{ Blood volume (expressed in cc.) } \\
\cline { 2 - 4 } & Controls & $\begin{array}{c}\text { Heart } \\
\text { failure }\end{array}$ & $\begin{array}{c}\text { Failuress: } \\
\text { controls }\end{array}$ \\
\hline & 75 Cases & 70 Cases & \\
Males & $\mathbf{7 , 5 2 8}$ & +983 \\
Total B.V. & 4,545 & $\mathbf{5 , 5 2 8}$ & +497 \\
Red cell V. & 2,018 & 2,515 & +486 \\
Plasma V. & 2,527 & 3,013 & \\
Hematocrit & $44.4 \%$ & $45.5 \%$ & \\
Average age & 49.5 yr. & 64.5 yr. & \\
\hline Females & 32 Cases & 32 Cases & \\
Total B.V. & 3,555 & 4,868 & $+1,313$ \\
Red cell V. & 1,477 & 2,041 & +564 \\
Plasma V. & 2,078 & 2,827 & +749 \\
Hematocrit & $41.6 \%$ & $42.0 \%$ & \\
Average age & 53.3 yr. & 58.7 yr. & \\
\hline
\end{tabular}

* Average values. 
TABLE II

Total, red cell and plarmo volume of contral patients and of cardiac patients in faiture and free of failure expressed as cubic contimeters per. kilogram of body weight*

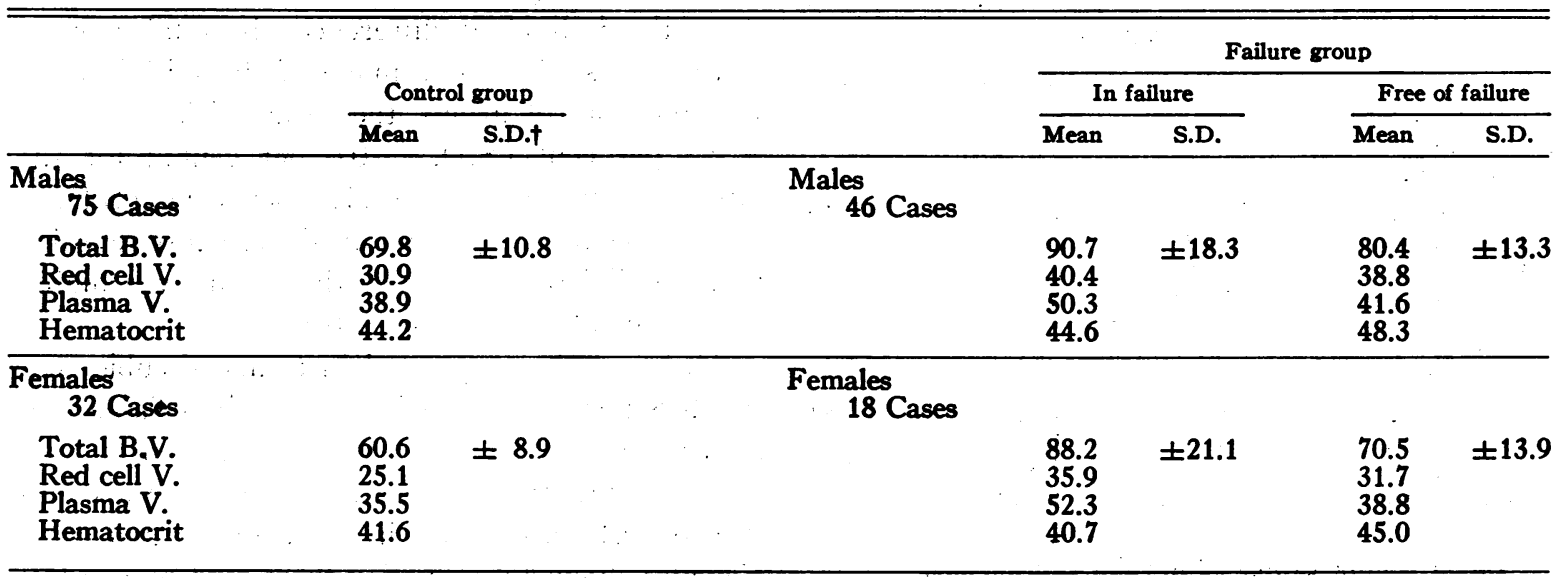

*Values for cardiac patients based on failure-free or "dry" weight.

† S.D. = Standard Deviation.

Frequency distribution diagrams of total blood volume in cubic centimeters per kilogram in these same groups are shown in Figures 1 and 2. Although patients in congestive heart failure had an average total blood volume significantly greater than patients without heart disease, there were some patients in heart failure whose total blood volume was within the range of normal.

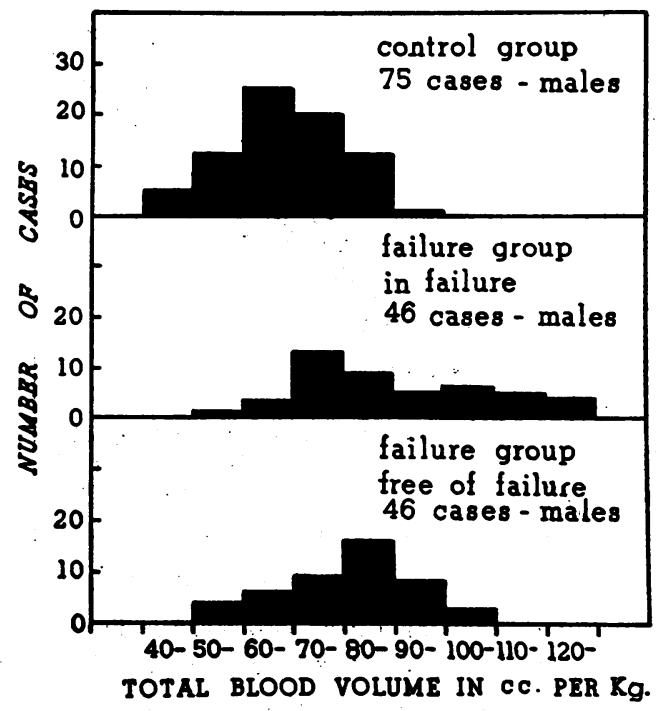

Fig. 1. Frequency Distribution Diagrams of Total Blood Volume in Cubic Centimeters per Kmogram or Body Weight in Two Groups of Male Patients: 1) Controls; 2) Cardiac Patents in Failure and Frere OF FAILURE
Heart failure to compensation versus repeat determinations in controls

In the control group of 55 patients who remained at bed rest for an average period of 9.5 days there was no significant difference between the averages of the initial and repeat determinations. In the congestive heart failure group of 78

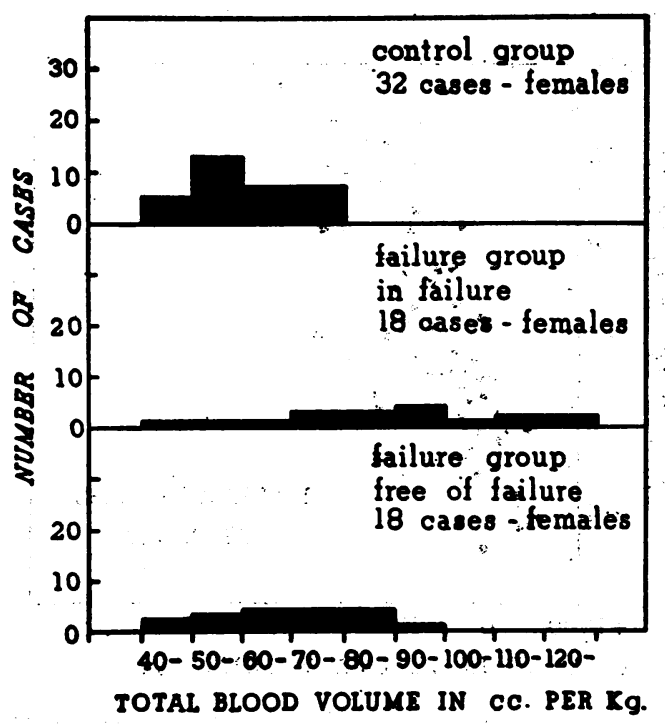

Fig. 2. Frequency Distribution Diagrams of Total Blood Volume in Cubic Centimeters per Krlogray of Body Weigtit in Two Groups of Fracale Patients : 1) Controls; 2) Carpiac Patients in Failure and Frem OF FAILURE 
TABLE III

Repeat determinations of blood volume in heart failure and control cases*

\begin{tabular}{lccc}
\hline \hline & \multicolumn{3}{c}{ Volume (average values) } \\
\cline { 2 - 4 } & $\begin{array}{c}\text { In } \\
\text { failure }\end{array}$ & $\begin{array}{c}\text { Free of } \\
\text { failure }\end{array}$ & $\begin{array}{c}\text { Loss or } \\
\text { gain }\end{array}$ \\
\hline $\begin{array}{c}\text { Heart failure } \\
\text { 78 Cases }\end{array}$ & & & \\
Total B.V. & 5,598 & 4,888 & -710 \\
Red cell V. & 2,463 & 2,340 & -123 \\
Plasma V. & 3,135 & 2,548 & -587 \\
Hematocrit & $44.1 \%$ & $47.9 \%$ & \\
\hline Controls & I & II & \\
55 Cases & & & \\
Total B.V. & 4,089 & 4,170 & +81 \\
Red cell V. & 1,765 & 1,797 & +32 \\
Plasma V. & 2,324 & 2,373 & +49 \\
Hematocrit & $43.1 \%$ & $42.9 \%$ & \\
\hline
\end{tabular}

* Blood volume expressed in cubic centimeters.

comparisons, where the average interval was 17.9 days between the initial determination in congestive failure and the repeat determination free of failure, there was a mean reduction of total blood volume of $710 \mathrm{cc}$. (See Table III.) This was due chiefly to a reduction in plasma volume with an accompanying rise in hematocrit from 44.1 per cent in failure to $\mathbf{4 7 . 9}$ per cent in the compensated state. The relation between rise in hematocrit and decrease in plasma volume in individual cases is shown in Figure 3.

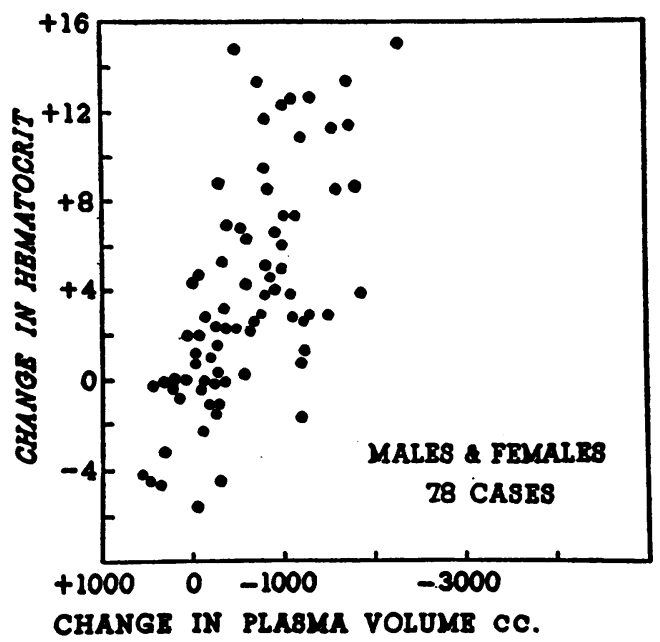

Fig. 3. Relation between Change in Hematocrit and Change in Plasma Volume during Recovery from Heart Failure

On the ordinate scale change in hematocrit is plotted from the direct reading, e.g., 40 per cent in failure to 50 per cent free of failure is plotted as +10 .
The individual values from these two series of repeat determinations are plotted in the diagrams of Figures 4 and 5. For statistical treatment the individual differences in total volume were expressed as percentage of the initial value. For the control group, the mean difference was +2.8 per cent (S.D. \pm 10.6 per cent); for the failure group, it was -11.3 per cent (S.D. \pm 13.6 per cent). Application of the $t$ test revealed that the difference between the means was highly significant $(t=7.0 ; \mathrm{P}<.001)$.

These results, expressed in terms of cubic centimeters per kilogram of body weight (Table II), showed that males had a mean reduction of total blood volume from $90.7 \mathrm{cc}$. per $\mathrm{Kg}$. in heart failure to $80.4 \mathrm{cc}$. per $\mathrm{Kg}$. in the compensated state. Females showed a reduction from $88.2 \mathrm{cc}$. per $\mathrm{Kg}$. in failure to $70.5 \mathrm{cc}$. per $\mathrm{Kg}$. in the compensated state. These mean reductions were significant: (Males, $t=3.35 ; \mathrm{P}<.01$ ); (Females, $t=2.53$; $\mathrm{P}<.05)$.

In this group of patients followed from congestive heart failure to compensation, there was a significant average reduction in total blood volume compared with a control group. This general statement can be given strong statistical sup-

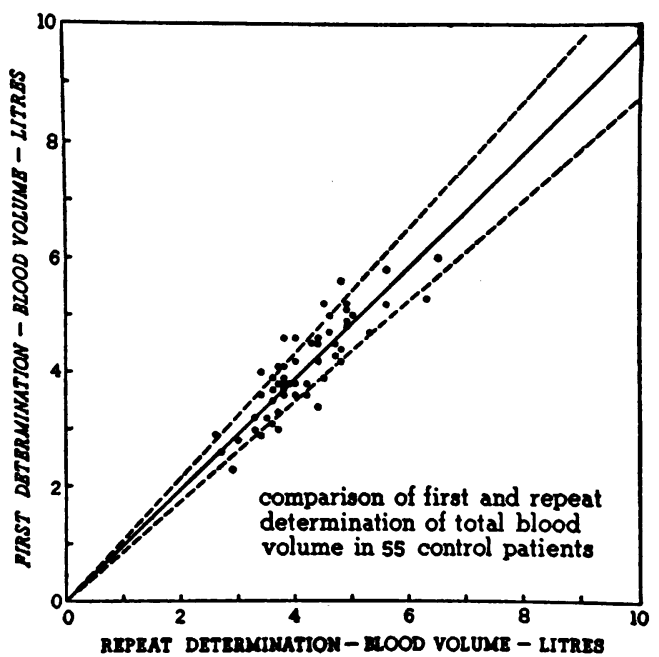

Fig. 4. Comparison of First and Repeat Determination of Total Blood Volume in 55 Control Patients

Average interval, 9.5 days. First determination plotted as the ordinate; repeat determination as the abscissa. The solid line passes through the mean of the initial versus repeat determinations. The interrupted lines embrace \pm 1 standard deviation of the individual differences about that mean. 


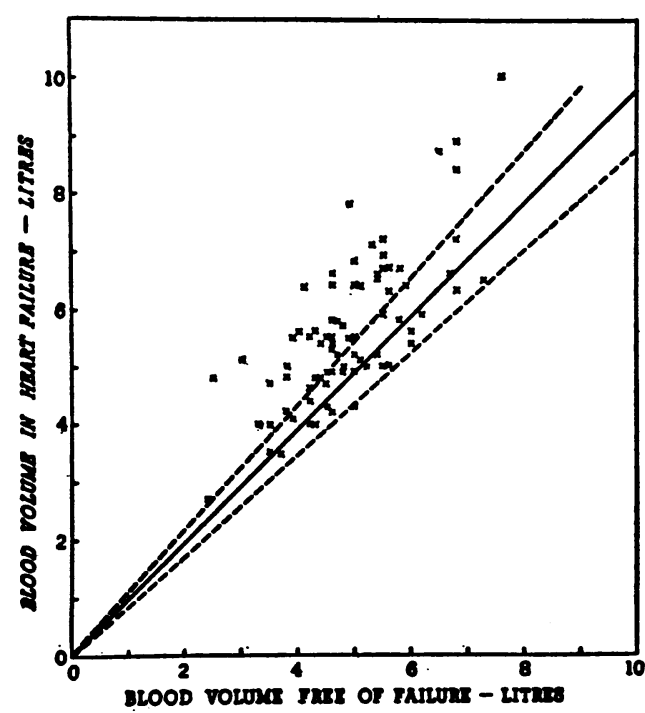

Fig. 5. Comparison of Blood Volume in Fanlure with Blood Volume Free of FaIlure in 78 Cases

Average interval 17.9 days. Blood volume in failure plotted as the ordinate; blood volume free of failure as the abscissa. Solid and interrupted lines are those of the control group in Figure 4. Points which fall above the solid line indicate a decrease in blood volume with compensation.

port but it does not imply that in each individual case of heart failure there was a reduction of blood volume with compensation. Of the 78 comparisons of blood volume, heart failure to compensation, the failure-free value fell below 2 S.D.'s of the control group comparisons in 21 cases, below 1 S.D. in 42, within \pm 1 S.D. in 25, and above 1 S.D. in only one case. (See Figure 5.) It is apparent that there are some cases of heart failure in which it is not possible to record an important reduction of blood volume with compensation.

\section{Compensation to heart failure}

The opportunity to compare the blood volume of patients re-admitted in failure with a prior determination in the compensated state occurred in sixteen cases. The average values are given in Table IV. There was an average increase in total blood volume of $\mathbf{5 1 0}$ cubic centimeters. Calculated on the basis of percentage increase in individual cases, the mean percentage increase was 11.9 per cent and was significant $(t=2.32 ; \mathrm{P}<$ $.05)$. This increase was due almost entirely to plasma; the red cell volume remained unchanged and the hematocrit fell from $\mathbf{4 9 . 8}$ per cent to $\mathbf{4 5 . 2}$ per cent with hemodilution. These changes are the reverse of those observed during recovery from heart failure where the plasma volume decreased and the hematocrit rose. Although there was a statistically significant mean increase, in eight cases the changes were slight, in eight there were large increases, and in none were there large decreases. There was no correlation between the size of the increase and the interval of time separating the two measurements.

\section{DISCUSSION}

The observations reported here indicate that in general the blood volume in congestive heart failure is greater than normal. This excess of blood is composed about equally of red cells and plasma. The plasma fraction decreases with compensation and increases again with congestive heart failure.

The red cell volume shows a small but statistically significant reduction with cardiac compensation. It is reasonable to assume that decrease in red cell mass would occur slowly, and that the average interval of eighteen days between the two determinations was not long enough to detect return of red cell volume to normal.

It is apparent from our results and from those of other investigators $(8,9)$ that some patients in advanced heart failure have a normal blood volume and that some patients may proceed to full compensation with no change in blood volume. The results of this study have been reviewed in a search for any factors in congestive heart failure which may be distinctive to the patients who have an increase in blood volume and to those who show a significant decrease with compensation.

There was no relation between the etiological

TABLE IV

Repeat determinations of blood volume: Compensation to heart failure-mean of $16^{*}$

\begin{tabular}{lccc}
\hline \hline & $\begin{array}{c}\text { Free of } \\
\text { failure }\end{array}$ & $\begin{array}{c}\text { In } \\
\text { failure }\end{array}$ & $\begin{array}{c}\text { Lose or } \\
\text { gain }\end{array}$ \\
\hline Total B.V. & 4,969 & $\mathbf{5 , 4 7 9}$ & $\mathbf{+ 5 1 0}$ \\
Red cell V. & 2,475 & 2,480 & $\mathbf{+ 5}$ \\
Plasma V. & 2,494 & $\mathbf{2 , 9 9 9}$ & $\mathbf{+ 5 0 5}$ \\
Hematocrit & $49.8 \%$ & $45.2 \%$ & \\
\hline
\end{tabular}

* Blood volume expressed in cubic centimeters. 
type of heart disease and either initial level of blood volume or the decrease with compensation except in pulmonary heart disease where the red cell volume was high.

Degree of heart failure in the sense of "leftsided" or "right-sided" did not bear on the problem since all the cases were of advanced "rightsided" congestive failure with all evidences of systemic venous congestion where that was: primarily of left ventricular, valvular or pulmonary origin.

It seemed reasonable to believe that : grossly edematous patients with their obvious excess of total body fluid would always have initially high plasma volumes and would show significant reduction of plasma volume after removal of the edema fluid, and that the reverse would hold for patients with little edema. It was, in fact, part of the theory of Warren and Stead (2) that plasma volume and extra-cellular fluid volume increased and decreased concordantly. To study this question the loss in body weight during recovery from congestive heart failure has been considered an approximate measure of the amount of edema originally present. The correlation between this loss in weight and the value for plasma volume in failure, in cubic centimeters per kilogram, is shown in Figure 6. There is no significant correlation: $r=.084 ; t=.645 ; \mathrm{P}>0.5$. Some patients with very little edema have a high plasma volume; other patients with massive edema have a normal plasma

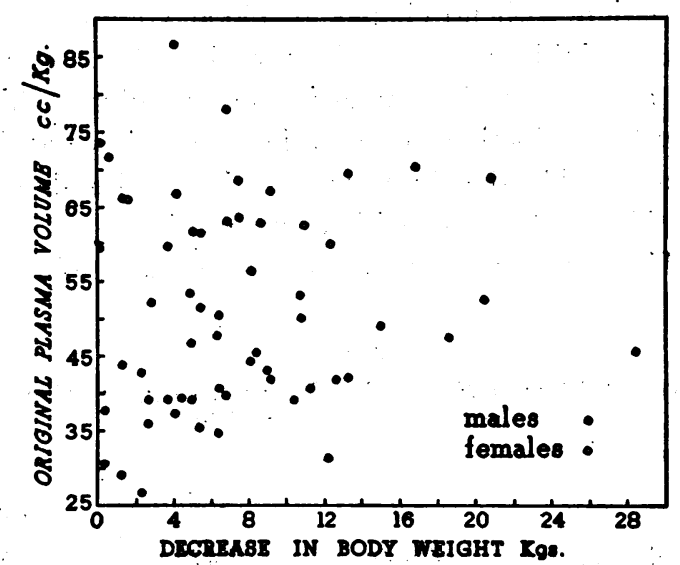

Fig. 6. Correfation between Plasma Voluge in Heart Failure in Cubic Centimeters per : Kmogram and Decrease in Body Weight during Recovery from Heart FaIIURB

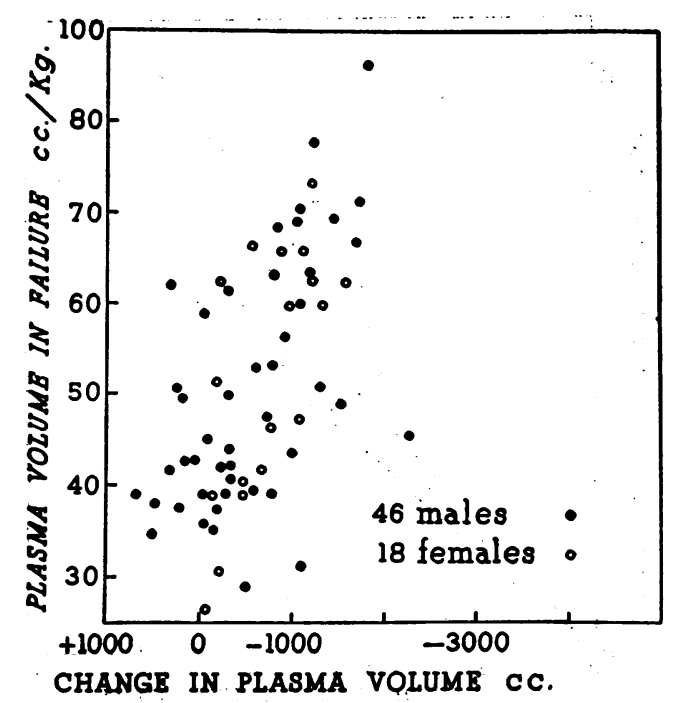

Fig. 7. Correlation between Plasma Volume in Heart Fanlure, in Cubic Centimeters per Kmogram, and Absolute Change in Plasma Volume in Cubic Centimeters during Recovery from Heart FaIlure

volume. By similar comparison, no correlation existed between the original amount of edema and degree of reduction of plasma volume during recovery from heart failure.

Because there were some decompensated cardiac patients with values for blood volume within the normal range and some who failed to show a reduction of blood volume with compensation, it seemed important to determine whether these two groups were composed for the most part of the same patients. For the group of patients whose total blood volume in heart failure was within the normal range (below $90 \mathrm{cc}$. per $\mathrm{Kg}$.; see Figures 1 and 2) the mean reduction of blood volume with compensation was 6.1 per cent. For the patients whose total blood volume in heart failure was above the normal range $(90 \mathrm{cc}$. per $\mathrm{Kg}$. or greater), the mean reduction with compensation was 16.5 per cent.

The correlation between original plasma volume in congestive failure, in cubic centimeters per kilogram, and absolute reduction in plasma volume, in cubic centimeters, was tested. (See Figure 7.) This correlation was significant $(r=0.54 ; t=$ $5.4 ; \mathrm{P}<.001)$. The correlation between original plasma volume in failure and per cent reduction of plasma volume with compensation was also significant: $(r=.45 ; t=4.3 ; \mathrm{P}<.001)$. 
These data indicate that those decompensated cardiac patients with normal total blood volume or plasma volume are the subjects who show unimportant reductions of volume with compensation. It is the patients with greater than normal values in failure who show the greatest reduction with compensation.

Etiological type of heart disease (except pulmonary) and amount of edema are apparently not determinants of the increase in blood volume which is usually present in congestive heart failure. We have been unable to determine any specific factors which are associated with this increase.

Some final emphasis must, therefore, be directed to the fact that a recordable increase in blood volume, and particularly of its plasma fraction, is not necessary for the development of the clinical picture of congestive heart failure even though it be the usual finding. "Congestion" may occur with a redistribution of blood to the venous side without an increase in blood volume.

Schreiber, Bauman, Yalow, and Berson (6) have reported that the mean ratio of body to venous hematocrit is .937 in control patients, .868 in patients with congestive heart failure, and .908 in patients free of failure. These differences in ratio imply that, where a tagged red cell method is used to determine total blood volume, comparisons between control patients, cardiac patients in congestive heart failure, and cardiac patients in the compensated state would be in error. The tendency would be to underestimate the differences: control versus heart failure; heart failure versus compensation.

We have reviewed our data with respect to the above observations. The net effect is to accentuate the mean differences already observed. That is, that blood volume is greater than normal in heart failure; that there is significant mean decrease with compensation; that there is significant mean increase on reversion to the state of failure. The correlations in Figures 6 and 7 remain virtually unchanged. However, there are still individual patients whose blood volume in heart failure is within the normal range; patients who proceed to compensation without significant change in blood volume; and patients who revert from compensation to heart failure without significant change.

\section{SUMMARY}

Blood volume studies by the $P^{23}$ tagged red blood cell method have been made on 102 patients in congestive heart failure and on 107 control patients.

Patients in congestive heart failure usually have a larget blood volume than controls.

With compensation there is usually a decrease in blood volume, principally of its plasma fraction.

With the spontaneous reappearance of congestive failure, the blood volume usually increases again.

Etiological type of heart disease and amount of edema do not determine the blood volume changes in heart failure, except pulmonary heart disease where the red cell volume is high.

In some cases of congestive heart failure blood volume may be normal, may not decrease with compensation or increase with the reappearance of failure.

\section{ACKNOWLEDGMENTS}

The authors wish to acknowledge the technical assistance of Miss Eha Johanson, B.Sc. and Miss Amy Britton, M. Sc.

The radioactive phosphorus used in this work was supplied by the Ontario Cancer Treatment and Research Foundation.

\section{REFERENCES}

1. Peters, J. P., The problem of cardiac edema. Am. J. Med., 1952, 12, 66.

2. Warren, J. V., and Stead, E. A., Jr., Fluid dynamics in chronic congestive heart failure. An interpretation of the mechanisms producing the edema increased plasma volume and elevated venous pressure in certain patients with prolonged congestive failure. Arch. Int. Med., 1944, 73, 138.

3. Gibson, J. G., 2nd, and Evans, W. A., Jr., Clinical studies of the blood volume. III. Changes in blood volume, venous pressure and blood velocity rate in chronic congestive heart failure. J. Clin. Invest., 1937, 16, 851.

4. Meneely, G. R., and Kaltreider, N. L., A study of the volume of the blood in congestive heart failure. Relation to other measurements in fifteen patients. J. Clin. Invest., 1943, 22, 521.

5. Seymour, W. B., Pritchard, W. H., Longley, L. P., and Hayman, J. M., Jr., Cardiac output, blood and interstitial fluid volumes, total circulating serum protein and kidney function during cardiac failure and after improvement. J. Clin. Invest., 1942, 21, 229. 
6. Schreiber, S. S., Bauman, A., Yalow, R. S., and Berson, $\mathrm{S}$. A., Blood volume alterations in congestive heart failure. J. Clin. Invest., 1954, 33, 578.

7. Reilly, W. A., French, R. M., Lau, F. Y. K., Scott, K. G., and White, W. E., Whole blood volume determined by radiochromium-tagged red cells. Comparative studies on normals and congestive heart failure patients. Circulation, 1954, 9, 571.

8. Prentice, T. C., Berlin, N. I., Hyde, G. M., Parsons, R. J., Lawrence, J. H., and Port, S., Total red cell volume, plasma volume, and sodium space in congestive heart failure. J. Clin. Invest., 1951, 30, 1471.

9. Ross, J. F., Chodos, R. B., Baker, W. H., and Freis, E. D., The blood volume in congestive heart failure. Tr. A. Am. Physicians, 1952, 65, 75.

10. Taylor, H. L., Erickson, L., Henschel, A., and Keyes, A., The effect of bed rest on the blood volume of normal young men. Am. J. Physiol., 1945, 144, 227.

11. Deitrick, J. E., Whedon, G. D., and Shorr, E., Effects of immobilization upon various metabolic and physiological functions of normal men. Am. J. Med., 1948, 4, 3.

12. Sjöstrand, T., Volume and distribution of blood, and their significance in regulating the circulation. Physiol. Rev., 1953, 33, 202.

13. Reid, A. F., and Orr, M. K., A rapid method for determining blood volumes by the use of $\mathrm{P}^{\mathrm{m}}$-labelled red cells. J. Clin. Invest., 1950, 29, 313.

14. Smith, H. P., Arnold, H. R., and Whipple, G. H., Blood volume studies. VII. Comparative values of Welcker, carbon monoxide and dye methods for blood volume determinations. Accurate estimation of absolute blood volume. Am. J. Physiol., 1921, 56, 336.

15. Gibson, J. G., 2nd, Peacock, W. C., Seligman, A. M., and Sack, T., Circulating red cell volume measured simultaneously by the radioactive iron and dye methods. J. Clin. Invest., 1946, 25, 838.

16. Gray, S. J., and Frank, H., The simultaneous determination of red cell mass and plasma volume in man with radioactive sodium chromate and chromic chloride. J. Clin. Invest., 1953, 32, 1000. 